\title{
Vinyl: A History of the Analogue Record
}

\author{
Richard Osborne \\ Farnham, UK: Ashgate Popular and Folk Music Series, 2012 \\ ISBN: 978-1-4094-4027-7 (HB)
}

\author{
Andrew Whelan \\ University of Wollongong, Australia \\ awhelan@uow.edu.au
}

Richard Osborne's Vinyl is a cultural history of that hallowed artefact: the vinyl record. Vinyl's merits essentially stand or fall on how one feels about the book's central conceit: it is divided into eight chapters, each of which addresses a discrete aspect of the disc. Osborne aims to present an account of this form, its development, triumph, persistence, and impact on the music by which it is disseminated, by breaking it down into its constituent components. Respectively: the groove; the disc; the label; vinyl; the LP; the 45; the B-side and the 12" single; and the sleeve.

Osborne traces the socio-cultural, aesthetic and to some extent the acoustic and technological development of each element, illuminating a number of longstanding debates in doing so. The structure of the book allows Osborne to develop a broad history of recorded music, pointing out and integrating numerous aspects of the format and its social signification that would otherwise appear distinct. The analytical discreteness of treating each aspect of the record separately enables the reader to reconceptualise what they know about the form and its context.

Osborne starts with the groove, covering Edison and the emergence of the phonograph, before turning to the cylinder-disc format war (30-31). We learn that Edison liked to play jazz records backwards; saying they sounded better that way (19). He debunks the conspiracy theory that the disc's dominance is the result of a capitalist plot to disbar amateur recording, ensuring the 'professionalisation' of music, by underscoring the roles played by regimes of taste and by consumers' aspirations for 'quality' (alongside the clever manipulation of these by the industry). The chapter on the label allows Osborne to situate these regimes in relation to the emergence of musical apartheid and as such the origins of the genre forms Billboard still features: Popular (now called Hot 100), Race (Hot R\&B/Hip-Hop) and Hillbilly (Hot Country). In the chapter on vinyl itself, Osborne shows how, prior to WWI, that amateurs could not record to shellac enhanced the format's 'aura', but as time passed the industrial nature of record production came to make it seem phoney. Hence the emergence of the 78 collector; and more broadly, the long cult of authenticity that vinyl has suffered and enjoyed: a cult to which the book is itself an offering.

In some respects the comparative lateness of some of the developments the book covers is surprising (for instance, the extremely close relation between the very idea of the LP as a single aesthetic 'package' and Sgt. Pepper), as is the critical role played by 
particular repertoires (such as Sinatra's constitutive relation to the development of the LP market). At the outset (4), Osborne declares his intention to focus on the US and UK and this feels like something of a missed opportunity. It begs a whole host of questions about what was happening elsewhere and in what ways that was different, but it also highlights the partial nature of Osborne's focus overall. Jamaican pioneers King Tubby and Lee Perry are together given one paragraph (154); for treatments of developments in other parts of the world, the reader must look elsewhere.

The structure of the book is something of a gamble in several senses. The framework is peculiar insofar as what is on or off the remit begins to appear somewhat arbitrary. Radio, cassette, jukeboxes, and digital forms of course make periodic appearances insofar as they impinge on or interact with vinyl, but at some level the discreteness of each aspect is difficult to maintain - where do records really 'begin' and 'end', and to what extent do they really have irreducible elements? To some extent the approach is belied in that the B-side and the 12" single are 'stuck together' as one chapter. Should the 12" receive its own chapter?

The style of the text is accessible, and periodically Osborne produces engaging valuations of his own, at one point asserting that Abba and Frank Wilson are "equally brilliant" (136), at another, producing the (to this reviewer) oxymoronic phrase: "Oasis's greatest achievements" (151). This makes for entertaining reading, but there are points where the book skirts close to dismissing out of hand that which is not vinyl. Osborne associates the decline of dance music with the decline of the 12" single, suggesting that the former might be due to the latter (159). To endorse this notion, we must pass aesthetic judgement on all the dance music currently in circulation (vinyl or otherwise). Osborne thus reproduces at points the vinylphilic discourses that a text such as this could explore, as when asserting that "it is hard to maintain attention throughout a single-sided CD" (as opposed to say, throughout Wagner's Der Ring des Nibelungen) and that "the art of sequencing has atrophied" (113).

Some readers may be disappointed by the absence of a theoretical frame for the work Osborne conducts. The narrative is focussed squarely on the vinyl; interesting ways of conceptualising vinyl (and indeed, the impact of vinyl on ways of conceptualising things) are largely passed over. Friedrich Kittler and Lisa Gitelman make brief appearances, Walter Benjamin makes several, although also brief. Neil Postman and Matthew Fuller do not feature. Somewhere there is a tantalising remix of the book waiting to be written by a fan of Bruno Latour.

The separation and isolation of the various elements of the record also segments and disrupts the historical narrative: to borrow a metaphor from another medium, we keep fast-forwarding and rewinding. In consequence, some historical junctures (the Battle of the Speeds, Sgt. Pepper) appear more than once. There is therefore a degree of repetition: to take one example, regarding the importance of Elvis to revenue at RCA Victor $(106,127)$. The chapters on the LP and the 45 essentially tell the same story, albeit from opposite directions.

At the heart of the book is the assertion that records are alive, because you can play them to death. Osborne's insight into the medium, and particularly its contrast with digital formats, is precise and compelling (183-184). Such is the skeuomorphic legacy of the parameters and structures imposed by the vinyl form, that labels, albums, and singles are still called labels, albums, and singles. A great value of Vinyl is its archaeology of all these forms, particularly given that many listeners today are likely unaware of the etymology even of the language used to describe the segmentation of music into these discrete packages, let alone the pragmatics of the emergence of the material forms which gave rise to it. 